Uniciencia. Vol. 29, No. 2, pp. 39-45. Julio-Diciembre, 2015.

ISSN Electrónico: 2215-3470

URL: www.revistas.una.ac.cr/uniciencia

Email: revistauniciencia@una.cr

DOI: http://dx.doi.org/10.15359/ru.29-2.3

\title{
Estudio de la actividad antibacteriana de los extractos orgánicos liquénicos obtenidos de Lobaria subdissecta y Parmotrema latissimum
}

Study of the antibacterial activity of the organic extracts from lichen Lobaria subdisecta and Parmotrema latissimum

Daniel Esquivel-Alvarado desquivel@cenat.ac.cr

Centro Nacional de Innovaciones Biotecnológicas (CENIBiot).

CeNAT-CONARE, San José, Costa Rica.

Gina Porras-Brenes

gporras@cenat.ac.cr

Centro Nacional de Innovaciones Biotecnológicas (CENIBiot).

CeNAT-CONARE,

San José, Costa Rica.

Sergio Madrigal-Carballo

smadrigal@cenat.ac.cr

Centro Nacional de Innovaciones Biotecnológicas (CENIBiot).

CeNAT-CONARE,

San José, Costa Rica.

Gerardo Rodríguez-Rodríguez

grodrig@una.ac.cr

Laboratorio de Fitoquímica, Escuela de Química.

Universidad Nacional,

Heredia, Costa Rica.

Recibido-Received: 3/jul/2014 / Aceptado-Accepted: 21/oct/2014 / Publicado-Published: 31/jul /2015.

\section{Resumen}

Se evaluó la actividad antimicrobiana de 4 extractos orgánicos de los líquenes Lobaria subdissecta y Parmoterma latissimum empleando el método de disco-difusión con una batería microbiana de 2 bacterias Gram positivas y 2 Gram negativas, todas de interés clínico humano. Se observó que los extractos no polares mostraron mayor actividad de inhibición del crecimiento de los microorganismos evaluados.

Palabras claves: actividad antimicrobiana; Lobaria subdisecta; Parmotrema lattisimum; método disco-difusión. 


\begin{abstract}
The antimicrobial activity was assessed in 4 organic extracts of the lichens Lobaria subdissecta and Parmoterma latissimum by using the disc-diffusion method utilizing a microbial battery of 2 bacteria Gram positive and 2 Gram negative, all of them of human and clinical interest. We noted that the nonpolar extracts showed more activity of grown inhibition of the bacterias test.
\end{abstract}

Keywords: Antimicrobial activity; Lobaria subdisecta; Parmotrema lattisimum; disc-diffusion method.

Los líquenes son la unión simbiótica entre un hongo (micobionte) y un fotobionte el cual puede ser un alga o una cianobacteria, cuya interacción origina un talo estable con estructura y fisiología especifica (Ramírez et al., 2005) Por su diversidad, adaptabilidad y composición química los líquenes son utilizados en la industria alimenticia, cosmetológica, farmacéutica y como indicadores de la contaminación (Fernández et al., 2003).

Son pioneros en la colonización de rocas, desintegrándolas para la formación de suelo, permitiendo el crecimiento de diversos tipos de vegetación rupícola o sexícola, musgos y ciertas plantas vasculares, jugando un papel importante en el ciclo de la materia en los ecosistemas. (Ramírez et al., 2005) El desarrollo estructural de los líquenes esta intrínsecamente relacionado con la asociación entre los tejidos del hongo, que rodea al fotobionte, generando las formas de costra (crustáceo), hoja (foliáceo), de diminutos arbustos (fruticoso) y gelatinosos (Hawksworth et al., 2000).

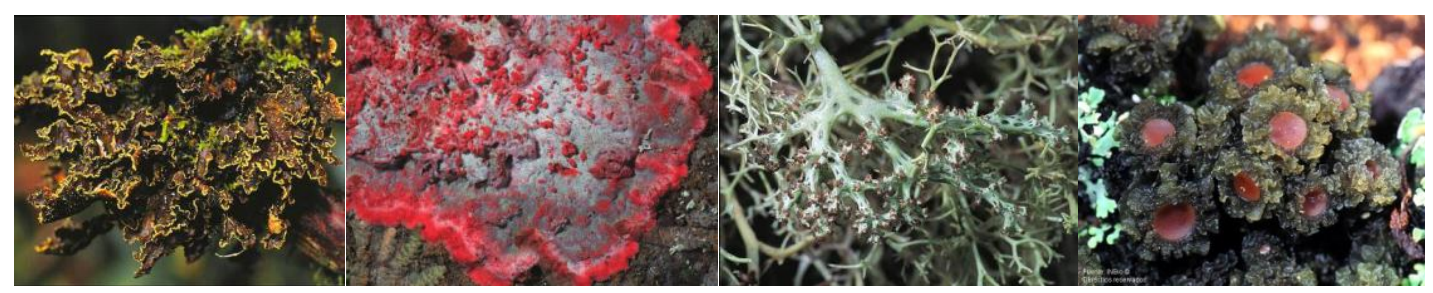

Figura 1.

Líquenes del tipo crustáceo, foliáceo, fruticoso y gelatinoso respectivamente. Fuente: (INBio)

Una de las características que conlleva la interacción entre un hongo y un alga para constituir un talo liquénico es la aparición de una serie de productos del metabolismo secundario que se depositan en grandes cantidades, en forma de diminutos cristales, sobre las hifas del micobionte. Además, la composición química cualitativa no parece verse modificada ni por la composición del sustrato ni por condiciones microambientales lo cual 
ha permitido el uso de estos metabolitos secundarios como buenos caracteres taxonómicos en muchos grupos de líquenes (Reol, 1989).

Entre los metabolitos secundarios que se encuentran en los líquenes están los ácidos alifáticos, para y metadépsidos, depsidonas, esteres bencílicos, dibenzofuranos, ácidos usneicos, xantonas, antraquinonas, terpenoides, derivados del ácido pulvínico los cuales se dividen de acuerdo a su ruta biosintética (Nash, 2008).

\section{Metodología}

\section{Recolecta y tratamiento del material vegetal}

Los líquenes Lobaria subdissecta y Parmotrema latissimum fueron colectados en las faldas del Volcán Irazú. Los líquenes se limpiaron de musgo y otros contaminantes empleando pinzas de cirugía. El material se secó a $40{ }^{\circ} \mathrm{C}$ por 72 horas y se molió utilizando un molino de cuchillas con un tamiz de $1 \mathrm{~mm}$.

\section{Obtención de los extractos crudos}

$10 \mathrm{~g}$ del material molido se extrajeron con $40 \mathrm{~mL}$ de distintos disolventes orgánicos (hexano, acetato de etilo, acetona y metanol). Las extracciones se realizaron utilizando un baño sónico durante 6 minutos y el proceso se repitió cinco veces. Seguidamente, los extractos fueron filtrados y el disolvente se eliminó utilizando un evaporador rotatorio. El sólido obtenido fue redisuelto a una concentración de 1 y $3 \mathrm{mg}$ para su almacenaje en viales color ámbar.

\section{Microorganismos}

Para evaluar la actividad antibacteriana se utilizó una batería con 4 microorganismos controles: Alcaligenes faecalis, Klebsiella pneumoniae, Pseudomonas aeruginosa y Staphylococcus aureus. Se prepararon suspensiones a partir de cada uno de estos microorganismos y se incubaron hasta alcanzar la fase logarítmica de crecimiento; la concentración fue ajustada al patrón 0,5 de la escala McFarland.

\section{Actividad antimicrobiana}

Para evaluar la actividad antimicrobiana in vitro se empleó el método de disco difusión en el medio Mueller-Hinton descrito por French y Hebert (1980). Las placas Petri con los extractos, Tween ${ }^{\circledR} 80$ y los controles fueron inoculadas con los microorganismos e incubados a $37^{\circ} \mathrm{C}$ por 24 horas.

\section{Resultados y Discusión}

Los resultados de las pruebas de disco-difusión de los extractos orgánicos de Lobaria subdissecta y Parmotrema latissimum evidenciaron que los disolventes puros y el Twen $^{\circledR} 80$ no generan ningún efecto contra las bacterias; situación que corrobora que los resultados obtenidos al evaluar la bioactividad de los extractos, son correspondientes a los metabolitos secundarios presentes en los mismos. 
Uniciencia. Vol. 29, No. 2, pp. 39-45. Julio-Diciembre, 2015.

Cabe recalcar que el antibiótico cloranfenicol® no obtuvo un halo de inhibición similar para todas las bacterias, debido a que se trata de bacterias pertenecientes a diferentes familias, los halos de inhibición que muestra el antibiótico, se debe a que inhibe la síntesis de proteínas bloqueando la actividad de la enzima peptidil transferasa al unirse a la subunidad 50S del ribosoma evitando la formación del enlace peptídico (Horton et al., 2008).

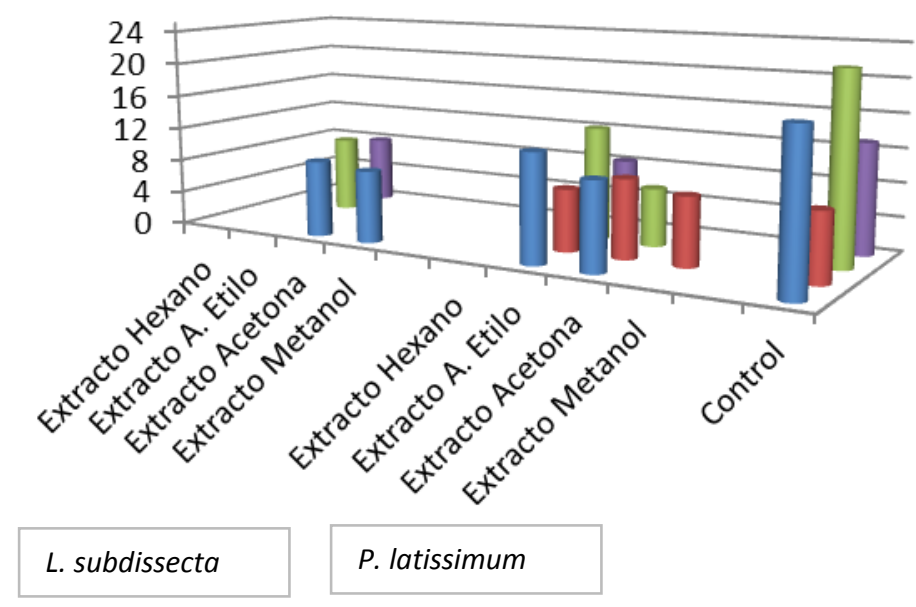

$$
\begin{aligned}
& \text { A. faecalis } \\
& \text { K. pneumoniae } \\
& \text { P. aeruginosa } \\
& \text { S. aureus }
\end{aligned}
$$

Figura 2.

Actividad antibiótica de los extractos liquénicos de $1 \mathrm{mg}$ contra las bacterias Alcaligenes faecalis, Klebsiella pneumoniae, Pseudomonas aeruginosa y Staphylococcus aureus utilizando la escala de McFarland 0,5.

Fuente: propia del estudio

Los extractos liquénicos de Parmotrema latissimum demostraron ser más activos que su homologo, tal y como se muestra en la figura 2. Esto puede deberse a sustancias específicas presentes en el mismo que inhiben el crecimiento de las bacterias. Se observa que para la bacteria Alcaligenes faecalis, el extracto de hexano de $P$. latissimum de $1 \mathrm{mg}$ generó un mayor diámetro de inhibición $(12,7 \pm 1,5 \mathrm{~mm})$ en comparación con el de $3 \mathrm{mg}$ $(10,0 \pm 2,6 \mathrm{~mm})$, lo cual puede ser justificado por un efecto de saturación del o de los metabolitos presentes. 
Uniciencia. Vol. 29, No. 2, pp. 39-45. Julio-Diciembre, 2015. URL: www.revistas.una.ac.cr/uniciencia

ISSN Electrónico: 2215-3470 Email: revistauniciencia@una.cr

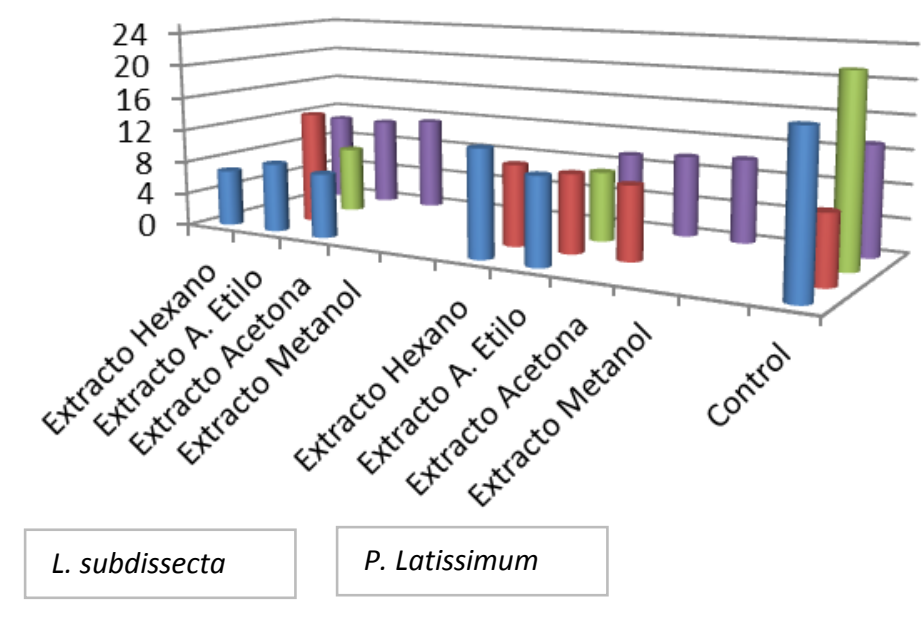

A. faecalis

K. pneumoniae

P. aeruginosa

S. aureus

Figura 3.

Actividad antibiótica de los extractos liquénicos de 3 mg contra las bacterias Alcaligenes faecalis, Klebsiella pneumoniae, Pseudomonas aeruginosa y Staphylococcus aureus utilizando la escala de McFarland 0,5.

Fuente: propia del estudio

En la figura 3, se observa que para la bacteria Alcaligenes faecalis los extractos no polares tienen un poder antibiótico más relevante en comparación a los polares, los cuales no registraron actividad. En el caso de la bacteria Klebsiella pneumoniae, sobresalen los extractos del liquen $P$. latissimum, para los cuales se observaron valores de actividad biológica superiores a los generados por patrón positivo de cloranfenicol®, lo cual es un argumento importante para futuras evaluaciones y estudios de este liquen contra la bacteria Klebsiella pneumoniae, sobretodo tomando en consideración el hecho de que el antibiótico es un compuesto puro de $30 \mu \mathrm{g}$ y el extracto es una mezcla compuesta de diversos metabolitos.

Asimismo se observa que los únicos extractos liquénicos que presentaron inhibición contra las cuatro bacterias fueron los de acetato de etilo para ambas especies de líquenes (Tabla 1). Los extractos estudiados presentaron la mejor acción inhibitoria contra la bacteria S. aureus, para la cual se observó que la actividad biológica de los mismos era independiente de la polaridad y directamente proporcional a la concentración evaluada. 
Uniciencia. Vol. 29, No. 2, pp. 39-45. Julio-Diciembre, 2015.

URL: www.revistas.una.ac.cr/uniciencia

Email: revistauniciencia@una.cr
ISSN Electrónico: 2215-3470

DOI: http://dx.doi.org/10.15359/ru.29-2.3

Tabla 1.

Actividad antibiótica de los extractos orgánicos de los líquenes Lobaria subdissecta y Parmotrema latissimum a 1 y 3 mg, contra las bacterias Alcaligenes faecalis, Klebsiella pneumoniae, Pseudomonas aeruginosa y Staphylococcus aureus utilizando la escala de McFarland 0,5.

\begin{tabular}{|c|c|c|c|c|c|c|c|c|c|c|c|c|c|c|c|c|c|}
\hline & & \multicolumn{4}{|c|}{ Alcaligenes faecalis } & \multicolumn{4}{|c|}{ Klebsiella pneumoniae } & \multicolumn{4}{|c|}{ Pseudomonas aeruginosa } & \multicolumn{4}{|c|}{ Staphylococcus aureus } \\
\hline & & \multicolumn{2}{|c|}{$1 \mathrm{mg}$} & \multicolumn{2}{|c|}{$3 \mathrm{mg}$} & \multicolumn{2}{|c|}{$1 \mathrm{mg}$} & \multicolumn{2}{|c|}{$3 \mathrm{mg}$} & \multicolumn{2}{|c|}{$1 \mathrm{mg}$} & \multicolumn{2}{|c|}{$3 \mathrm{mg}$} & \multicolumn{2}{|c|}{$1 \mathrm{mg}$} & \multicolumn{2}{|c|}{$3 \mathrm{mg}$} \\
\hline & & $\begin{array}{l}\mathrm{mm} \\
\text { Inh. }\end{array}$ & $\begin{array}{c}\text { D.E. } \\
\pm\end{array}$ & $\begin{array}{l}\mathrm{mm} \\
\mathrm{Inh} .\end{array}$ & $\begin{array}{c}\text { D.E. } \\
\pm\end{array}$ & $\begin{array}{l}\mathrm{mm} \\
\text { Inh. }\end{array}$ & $\begin{array}{c}\text { D.E. } \\
\pm\end{array}$ & $\begin{array}{l}\mathrm{mm} \\
\text { Inh. }\end{array}$ & $\begin{array}{c}\text { D.E. } \\
\pm\end{array}$ & $\begin{array}{l}\mathrm{mm} \\
\text { Inh. }\end{array}$ & $\begin{array}{c}\text { D.E. } \\
\pm\end{array}$ & $\begin{array}{l}\mathrm{mm} \\
\mathrm{Inh} .\end{array}$ & $\begin{array}{c}\text { D.E. } \\
\pm\end{array}$ & $\begin{array}{l}\mathrm{mm} \\
\mathrm{Inh} .\end{array}$ & $\begin{array}{c}\text { D.E. } \\
\pm\end{array}$ & $\begin{array}{l}\mathrm{mm} \\
\mathrm{Inh} .\end{array}$ & $\begin{array}{c}\text { D.E. } \\
\pm\end{array}$ \\
\hline \multirow{4}{*}{ 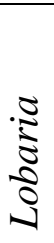 } & Extracto Hexano & - & - & 6,8 & 0,8 & - & - & - & - & - & - & 9,0 & 1,0 & - & - & 10,7 & 2,1 \\
\hline & Extracto Acetato de etilo ${ }^{*}$ & 9,0 & 0,0 & 8,3 & 0,6 & - & - & 13,5 & 2,1 & 9,0 & 0,0 & 11,7 & 2,1 & 8,8 & 0,8 & 10,7 & 0,3 \\
\hline & Extracto Acetona ${ }^{*}$ & 8,5 & 0,0 & 7,7 & 1,0 & - & - & - & - & - & - & 10,3 & 0,6 & - & - & 11,3 & 1,5 \\
\hline & Extracto Metanol $^{*}$ & - & - & - & - & - & - & - & - & - & - & 9,3 & 1,1 & - & - & - & - \\
\hline \multirow{4}{*}{$\begin{array}{c}\mathfrak{5} \\
\vdots \\
\vdots \\
\vdots \\
\vdots \\
\vdots \\
\vdots \\
2\end{array}$} & Extracto Hexano $^{*}$ & 12,7 & 1,5 & 10,0 & 2,6 & - & - & - & - & - & - & 9,5 & 0,7 & - & - & - & - \\
\hline & Extracto Acetato de etilo* & 10,3 & 0,6 & 11,7 & 1,5 & 7,3 & 0,6 & 9,7 & 1,2 & 13,3 & 0,6 & 13,0 & 1,7 & 8,3 & 0,6 & 9,3 & 0,6 \\
\hline & Extracto Acetona ${ }^{*}$ & - & - & - & - & 9,2 & 0,3 & 9,3 & 1,2 & 6,8 & 0,4 & 8,0 & 1,0 & - & - & 9,7 & 0,6 \\
\hline & Extracto Metanol ${ }^{*}$ & - & - & - & - & 8,0 & 1,0 & 8,7 & 1,2 & - & - & - & - & - & - & 10,0 & 0,0 \\
\hline & Control (cloranfenicol ${ }^{\circledR}$ ) & 18,0 & 0,0 & 18,0 & 0,0 & 8,0 & 0,0 & 8,0 & 0,0 & 22,0 & 0,0 & 22,0 & 0,0 & 13,0 & 0,0 & 13,0 & 0,0 \\
\hline & Tween $^{\circledR} 80$ & - & - & - & - & - & - & - & - & - & - & - & - & - & - & - & - \\
\hline & Hexano & - & - & - & - & - & - & - & - & - & - & - & - & - & - & - & - \\
\hline & Acetato de Etilo & - & - & - & - & - & - & - & - & - & - & - & - & - & - & - & - \\
\hline & Acetona & - & - & - & - & - & - & - & - & - & - & - & - & - & - & - & - \\
\hline & Metanol & - & - & - & - & - & - & - & - & - & - & - & - & - & - & - & - \\
\hline
\end{tabular}

Daniel Esquivel-Alvarado y otros

Artículo protegido por licencia Creative Commons: BY-NC-ND / Protected by Creative Commons: BY-NC-ND

Revista de acceso y publicación gratuita/ Access and publication in Uniciencia is totally no fee. 
Uniciencia. Vol. 29, No. 2, pp. 39-45. Julio-Diciembre, 2015.

URL: www.revistas.una.ac.cr/uniciencia

ISSN Electrónico: 2215-3470

Email: revistauniciencia@una.cr

\section{Conclusiones}

Los extractos del liquen Lobaria subdissecta presentaron diámetros de inhibición mayores contra las bacterias Alcaligenes faecalis, Klebsiella pneumoniae y Staphylococcus aureus. También se observaron casos donde el uso de un extracto más concentrado no siempre garantizó la generación de halos de inhibición de mayor diámetro. Los extractos de acetato de etilo, evaluados contra las distintas bacterias, presentaron los mayores halos de inhibición y éstos, se observaron en casi todas los microorganismos estudiados excepto en Klebsiella pneumoniae a una masa de $1 \mathrm{mg}$.

En futuras investigaciones se recomienda realizar la prueba de disco-difusión variando las concentraciones de McFarland's así como también, realizar un estudio cromatográfico (HPLC) de los metabolitos secundarios presentes en los extractos activos, con el propósito de identificar el o los compuestos responsables de la actividad biológica observada.

\section{Referencias}

Fernández, A. y Terrón, A. (2003). Biomonitorización de la calidad del aire en los alrededores de La Robla (León). Ecosistemas. 12(2), 1-11.

French, E. y Hebert, T. (1980). Método de investigación fitopatológica. Primera edición. Editorial IICA. San José. Costa Rica. P. 24.

Hawksworth, D., Iturriaga, T. y Crespo, A. (2000). Líquenes como bioindicadores inmediatos de contaminación y cambios medio-ambientales en los trópicos. Rev Iberoam Micol. 22, 71-82. DOI http://dx.doi.org/10.1016/S1130-1406(05)70013-9

Horton, R., Moran, L., Scrimgeour, G., Perry, M., y Rawn, D. (2008). Principios de Bioquímica. 4ta. Edición. Pearson Educación. México. 700-701.

Nash, T. (2008), Lichen biology. $2^{\text {nd. }}$ Edition, Cambridge University Press, United Kingdom, 8-9. DOI http://dx.doi.org/10.1017/CBO9780511790478

Ramírez, A. y Cano, A. (2005). Líquenes de Pueblo Libre, una localidad andina en la Cordillera Negra (Huaylas, Ancash, Perú). Rev.peru.biol. 12(3), 383-396.

Reol, M. (1989). Aplicación de técnicas analíticas e interpretación de las variaciones químicas en liqúenes. Anales Jard. Bot. Madrid. 46(1), 249-257.

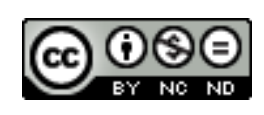

Estudio de la actividad antibacteriana de los extractos orgánicos liquénicos obtenidos de Lobaria subdissecta y Parmotrema latissimum (Daniel Esquivel-Alvarado y otros) por Revista Uniciencia se encuentra bajo una Licencia CreativeCommons Atribución-NoComercial-SinDerivadas 3.0 Unported

Daniel Esquivel-Alvarado y otros

Artículo protegido por licencia Creative Commons: BY-NC-ND / Protected by Creative Commons: BY-NC-ND

Revista de acceso y publicación gratuita/ Access and publication in Uniciencia is totally no fee. 